University of St. Thomas, Minnesota

UST Research Online

2013

\title{
How does an initial expectation bias influence auditors' application and performance of analytical procedures?
}

\author{
Byron Pike \\ Minnesota State University - Mankato, byron.pike@mnsu.edu \\ Mary B. Curtis \\ University of North Texas, mary.curtis@unt.edu \\ Lawrence Chui \\ University of St. Thomas, Minnesota, lawrence.chui@stthomas.edu
}

Follow this and additional works at: https://ir.stthomas.edu/ocbacctpub

Part of the Accounting Commons

This Article is brought to you for free and open access by the Accounting at UST Research Online. It has been accepted for inclusion in Accounting Faculty Publications by an authorized administrator of UST Research Online. For more information, please contact asle4660@stthomas.edu. 
2013

\title{
How Does an Initial Expectation Bias Influence Auditors' Application and Performance of Analytical Procedures?
}

\author{
Byron J. Pike \\ Minnesota State University, Mankato \\ Mary B. Curtis \\ University of North Texas \\ Lawrence Chui \\ University of St. Thomas
}

\begin{abstract}
Prior research demonstrates that knowledge of unaudited balances biases auditors' expectations during analytical procedures. What is less understood is how these biases affect auditors' subsequent investigations and their conclusions about the reasonableness of a particular balance. We employ the selective accessibility model to examine the differences in analytical procedure performance when auditor expectations are formed with versus without knowledge of the client's unaudited financial statement balances. In an experimental setting, we found that auditors with knowledge of unaudited balances favored hypotheses and supporting information indicating that the client's balance was reasonably stated. Auditors who formed expectations without current-year figures were more willing to evaluate competing alternatives, could better identify the most pertinent information, and were significantly more likely to identify a material misstatement using an analytical procedure.
\end{abstract}

Keywords: auditor judgment; analytical procedures; numerical anchoring; selective accessibility.

Data Availability: Data are available from the authors on request.

This research project has benefited from helpful comments from Larry Davis, Mark Davis, Alan Mayper, Barbara Merino, Robert Pavur, Linda Quick, Jesse Robertson, Brian Shapiro, Neil Wilner, and the participants at the 2011 AAA Section Midyear Meeting. We also thank Steve Asare and Arnold Wright for access to their original instrument.

This paper is derived from Byron J. Pike's dissertation.

Editor's note: Accepted by Kathryn Kadous. 


\section{INTRODUCTION}

A nalytical procedures, an evidence-gathering process, play an important role in today's risk-based audits. The technique includes comparing a client's unaudited balance to an independent expectation developed by auditors. ${ }^{1}$ Although this test is one of the most efficient available to auditors, its efficiency may come at the price of effectiveness: decision-making may be negatively influenced by the timing of knowledge acquisition pertaining to the current-year balances.

When performing analytical procedures, auditors use their knowledge of the client, industry, and economic conditions to develop an expectation for the client's recorded balance. If auditors' resulting expectations are materially consistent with the unaudited balance and possess a desired level of precision, then the analytical procedure can be relied on as an appropriate form of audit evidence; otherwise, auditors must do additional work to ascertain the reasonableness of the balance under investigation (AICPA 1988; PCAOB 2010).

Although irrelevant to the development of an expectation point estimate, auditors typically have access to current-year unaudited balances during analytical procedures (Trompeter and Wright 2010). Unfortunately, both accounting and psychology research have found that individuals tend to incorporate available, yet irrelevant, information into their expectation formations, which can result in expectations that are biased in the direction of the irrelevant target (Tversky and Kahneman 1974; Kinney and Uecker 1982; Biggs and Wild 1985; Heintz and White 1989; McDaniel and Kinney 1995; Heintz et al. 1999). Some researchers have hypothesized that expectation bias could undermine analytical procedures and result in the incorrect acceptance of a materially misstated balance (Kinney and Uecker 1982). While it is well documented that expectation formation with knowledge of unaudited balances translates into biased expectations (Biggs and Wild 1985; Heintz and White 1989; McDaniel and Kinney 1995; Heintz et al. 1999), it is unknown how such expectations influence the subsequent stages of analytical procedures and auditors' conclusions about the reasonableness of a particular balance.

It is critically important to determine how judgment biases can impact analytical procedures, given their growing prevalence and significance within current audit methodology (SAS No. 104 through SAS No. 111, AICPA 2008a; PCAOB 2007), as well as identified problems with their application (PCAOB 2008a; Ranzilla et al. 2011). Therefore, the purpose of this paper is to examine the differences in analytical procedure performance when auditor expectations are formed with versus without knowledge of the client's unaudited financial statement balances. We employ the selective accessibility model to guide our investigation (Mussweiler 1997; Mussweiler and Strack 1999a; Strack and Mussweiler 1997).

To assess the decision process, we executed an analytical procedure experiment with senior-level auditors. After manipulating the timing of when the auditors received the client's current-year figures (before versus after expectation formation), we examined auditors' investigation into a fluctuation. The results indicate that an expectation formed with knowledge of unaudited balances adversely affected auditors' subsequent investigation and resulting judgment quality. In particular, those auditors favored hypotheses and supporting information indicating the

1 Analytical procedure expectations can encompass point estimates (reasonableness tests), ratios analysis, trend analysis, or comparisons to industry averages. A survey of practitioners found auditors use point estimates approximately 70 percent of the time in their application of analytical procedures (Trompeter and Wright 2010). This paper is focused exclusively on auditors' expectations and subsequent investigations pertaining to point estimates. Thus, expectation formation and application of analytical procedures are described from this perspective. Other types of expectation formation may not involve the level of detail described and tested in this study. While the approach described herein can be applied to any type of analytical procedure, it is particularly relevant to substantive analytical procedures since they require a higher level of precision. 
client's balance as reasonably stated, and they failed to give alternative hypotheses equal consideration. Auditors without unaudited balances during expectation formation were more willing to give consideration to all available hypotheses and could better identify the additional information most pertinent to the decision. As a result, auditors who formed expectations without knowledge of unaudited balances were significantly more likely to identify a material misstatement using an analytical procedure.

Prior analytical procedure research has focused either on auditors' expectation formation (cf. Heintz et al. 1999) or how auditors investigate and reach conclusions about fluctuations (cf. Asare and Wright 2003). Despite this significant body of research, little is known regarding how biases created during the initial step of this process actually flow through and influence analytical procedures. Therefore, our contribution to the accounting literature is to investigate the impact of unaudited balances on auditors' performance of the subsequent stages of analytical procedures. We also answer the call for research that goes beyond the identification of factors that diminish decision quality and provide evidence on how biases influence decision-making and auditor effectiveness (Nelson 2005, 64).

We also contribute to the growing psychology research examining numerical anchoring. Tversky and Kahneman (1974) identified the anchoring heuristic more than 35 years ago, yet debate continues regarding the mechanisms that cause the anchoring phenomenon (Wegener et al. 2010a; Frederick et al. 2010; Epley and Gilovich 2010; Russo 2010). Furthermore, little is known about the consequences of judgments after a biased estimate (Wegener et al. 2010b). Through using an analytical procedure in an anchoring environment, we provide additional evidence on selective accessibility as a means of explaining why and how anchoring occurs, as well as its impact on subsequent decisions.

Section II presents our literature review and hypothesis development. Section III details the research methodology used in this paper. Section IV presents the results of our experiment. Finally, Section V discusses conclusions, limitations, and areas for future research.

\section{LITERATURE REVIEW AND HYPOTHESIS DEVELOPMENT}

\section{Analytical Procedures}

Since 1988, planning and review analytical procedures have been required for all audit engagements, and substantive analytical procedures are allowed at the discretion of auditors to obtain principle audit evidence (AICPA 2008). ${ }^{2}$ The type of analytical procedure (planning, substantive, or review) is typically differentiated by the timing of application and the amount of precision used in auditors' expectations. Point estimates, the focus of this study, are not only the most prevalent form of analytical expectation (Trompeter and Wright 2010), but also are inherently precise (AICPA 2012).

Regardless of the type of analytical procedure, the process is largely the same. Auditors first develop an independent expectation of what they expect the client's current-year balance should be. Next, they compare their expectation to the client's unaudited balance. If no material difference exists between the auditors' expectation and the client's balance, then the amount is deemed appropriate, and the procedures performed are documented. On the other hand, if a material

\footnotetext{
2 Analytical procedures are particularly important to the business risk audit (BRA) methodology. The BRA, a riskbased approach focusing heavily on control testing and the use of analytical procedures in an attempt to achieve an effective, but more efficient, audit, has now become the predominant audit methodology (Cullinan and Sutton 2002; Robson et al. 2007). Indeed, both the Public Company Accounting Oversight Board (PCAOB 2007) and American Institute of Certified Public Accountants (SAS No. 104 through SAS No. 111, AICPA 2008a) have issued audit standards that either require or promote the use of the BRA methodology.
} 
difference exists, then this fluctuation warrants further investigation (AICPA 1988). This further investigation, largely cognitive in nature, consists of identifying hypotheses, information search, and hypothesis evaluation and is typically based on the examination of additional information. Auditors then make a final reasonableness assessment to determine whether the client's balance is reasonably stated or requires an adjustment (Koonce 1993).

\section{Prior Analytical Procedures Research}

The research analyzing auditors' performance of analytical procedures has either focused on the formation of initial expectations or the investigation of fluctuations. Expectation formation research has examined whether knowledge of unaudited balances biases auditor expectations. From a normative perspective, the client's unaudited balance should not influence auditor expectations. Procedurally, the client's reported current-year balance should only be considered after auditors have developed an expectation. If auditors consider the client's unaudited balance when forming their expectations, then their analytical procedure is based on circular reasoning.

This research finds two consistent themes. First, when unaudited balances are provided to auditors during expectation formation, auditors tend to create estimates in the direction of the current-year amount (Kinney and Uecker 1982; Biggs and Wild 1985; Heintz and White 1989; McDaniel and Kinney 1995; Heintz et al. 1999). This tendency is prominent regardless of the financial trend in the financial statements (Heintz and White 1989) and the amount of prior-year information provided to the auditors (Biggs and Wild 1985). Second, this research has repeatedly found that auditors who create biased expectations request additional information at a rate that is indistinguishable from auditors who form expectations without unaudited balances; however, these studies never continued to the next step of supplying the participants with additional information from which to evaluate their expectations (Kinney and Uecker 1982; Biggs and Wild 1985; Heintz and White 1989).

Prior research has also examined the cognitive process by which auditors investigate and reach conclusions about fluctuations identified during analytical procedures. These fluctuations are of course a result of auditors' expectation formation process and the client's reported balances. However, these studies typically begin by telling participants that a fluctuation warranting additional investigation exists within the financial statements. Researchers then examine one or more of the cognitive components used to investigate the balance of interest. These studies have generated a wide variety of findings regarding how auditors investigate, analyze, and reach conclusions during analytical procedures. For instance, this research has found that the following all impact auditors' ability to identify the correct cause of a fluctuation:

- experience (O’Donnell 2002; Lin et al. 2003),

- information search strategies (O’Donnell and Lehman 1999; O’Donnell 2004),

- hypothesis sets (Bhattacharjee et al. 1999; Luippold and Kida 2012),

- accountability (Peecher 1996; Asare et al. 2000),

- decision aids (Anderson and Koonce 1998; Mueller and Anderson 2002; Anderson et al. 2003),

- problem representations/mental models (Bierstaker et al. 1999; O’Donnell and Perkins 2011; Brewster 2012),

- time constraints (Bhattacharjee et al. 1999; Asare et al. 2000),

- type of financial statement error (Green and Trotman 2003; Law and Willett 2004), and

- inconsistent information (Asare and Wright 2003).

Despite this seemingly significant body of research, it is unknown how an initial expectation bias flows through and influences the subsequent analytical procedure process. 


\section{Theoretical Development}

To bridge this gap in the understanding of analytical procedures bias, we propose the selective accessibility model as the theoretical basis for predicting the actions of auditors during their performance of analytical procedures. This model was proposed and tested by psychology researchers as a means of explaining the anchoring tendency identified by Tversky and Kahneman (1974) and its impact on decision-making (Mussweiler 1997; Mussweiler and Strack 1999a, 1999b, 2000a, 2000b; Strack and Mussweiler 1997). The model is the most widely accepted mechanism for explaining anchoring, and is driven by the premise that knowledge content activation and cognitive processing differ depending on whether a target is available during a task requiring estimation or comparison.

When applied to tasks requiring estimation, the model predicts that individuals who have access to a target will selectively retrieve knowledge consistent with the provided target. This selective activation results in the creation of estimates that are arbitrarily close to the provided target, even when the target is irrelevant to the decision (Chapman and Johnson 1999; Mussweiler 1997; Mussweiler and Strack 1999a, 1999b, 2000a, 2000b; Strack and Mussweiler 1997). On the other hand, when no target is present, individuals have no basis upon which to be selective and, thus, access a broader range of knowledge relevant to the task. This leads to deliberate cognitive processing of all available information because one does not have the target-influenced subset of information needed to make quick, intuitive decisions (Kahneman 2003; Epley 2004). This anchoring bias is well documented in the psychology and accounting literatures, as well as in many other disciplines.

What is less understood and explored are the consequences of judgments after a biased estimate (Wegener et al. 2010b). The selective accessibility model goes beyond numerical anchoring by also describing how hypothesis testing and final judgments are influenced by the availability of a target. The assumption behind the model is that the activated knowledge, whether selective or broad ranging, remains accessible and influences subsequent decisions. In particular, individuals with selective knowledge activation, resulting from having access to a target, tend to narrow the hypothesis set under consideration down to the hypotheses indicating that the target is reasonable based on their estimate (Chapman and Johnson 1999; Mussweiler 1997; Mussweiler and Strack 1999a, 1999b, 2000a, 2000b; Strack and Mussweiler 1997). These hypotheses become the primary explanation considered, and individuals search for information in support of the salient hypotheses and fail to give equal consideration to other explanations. Moreover, alternative hypotheses suggesting that the target is inappropriate are prematurely discarded because the person's knowledge related to those hypotheses is difficult to recall or less accessible.

In contrast, individuals without targets tend to access all of their knowledge and evaluate a broader set of possible explanations or solutions, resulting in the inclination to consider multiple, competing causes for a fluctuation (Epley and Gilovich 2005). By giving consideration to a broader range of information, individuals with unbiased expectations are more likely to identify additional information most relevant to the decision. Moreover, without prematurely committing themselves to a particular explanation, they are more likely to reach a correct final judgment, which includes identifying the hypothesis that best explains the relationships among the underlying data (Chapman and Johnson 1999; Mussweiler 1997; Mussweiler and Strack 1999a, 1999b, 2000a, 2000b; Strack and Mussweiler 1997).

\section{Predictions}

Prior literature indicates auditors with knowledge of unaudited balances during expectation formation will develop biased expectations, as compared with auditors without such knowledge (Kinney and Uecker 1982; Biggs and Wild 1985; Heintz and White 1989; McDaniel and Kinney 
1995; Heintz et al. 1999). Since this is already established in the literature, we begin our predictions at the next step in the analytical procedures process. After comparing their point estimate to the client's balance, auditors identify a list of possible causes for the fluctuation (hypothesis set) and consider the merits of each explanation. Our theory predicts that auditors with knowledge of unaudited balances will narrow the hypothesis set to include only those supporting the reported amount as reasonably stated because the selective activation of knowledge makes such an explanation appear more plausible. In contrast, auditors who form expectations without unaudited balances activate a broader knowledge set. They are therefore more inclined to consider competing or alternative causes for the fluctuation. This leads to the following hypothesis:

H1: Auditors who form expectations with knowledge of unaudited balances will assign a greater likelihood of explanation to non-error hypotheses than auditors who form expectations without knowledge of unaudited balances.

Selective knowledge activation by auditors with biased expectations will focus their attention on additional information supporting the non-error hypotheses. Specifically, these auditors will focus on anchor-consistent information and base judgments primarily on this biased subset of information. As a result, these auditors should assign greater weight to the additional information supporting the non-error hypotheses that suggest the client's balance is reasonable, perhaps even in the presence of a material misstatement. Auditors who are unaware of the client's current-year balances should be more willing to examine alternative hypotheses and evaluate more of the available information. As a result, they should be able to identify evidence most pertinent to a final decision about the analytical procedure. Based on these predictions, the next hypothesis is:

H2: Auditors who form expectations with knowledge of unaudited balances will assign greater weight to the additional information that supports the non-error hypotheses, while auditors who form expectations without knowledge of unaudited balances will assign greater weight to the additional information that correctly explains the fluctuation in the client's unaudited balance.

When auditors revisit the hypothesis set and select the best explanation for the fluctuation, our theory predicts that auditors without knowledge of unaudited balances during expectation formation should attend to more of the information provided during the analytical procedure. This openness to greater possibilities increases the likelihood they will identify the relationship between the data and the client's reported balance. This leads to the following hypothesis:

H3: Auditors who form expectations with (without) knowledge of unaudited balances are less (more) likely to identify the correct cause behind the client's current-year fluctuation.

Additionally, the difference in cognition between auditors who form expectations with versus without unaudited balances will likely influence the perceived reasonableness of the current-year balance after all the audit procedures are performed. In particular, auditors with knowledge of unaudited balances will base their estimates primarily on evidence that has been made easily accessible through selective activation. Thus, when asked to assess the reasonableness of the unaudited balance, these auditors are expected to view the reported amount more favorably than auditors who only gain such knowledge after their expectation is formed. As a result, we propose the final hypothesis:

H4: Auditors who form expectations with (without) knowledge of unaudited balances will make more (less) favorable final assessments about the reasonableness of the client's reported balance. 


\section{RESEARCH METHOD}

\section{Participants}

A total of 61 experienced senior-level auditors, attending their Big 4 audit firm's national senior-in-charge training session, participated in this study. ${ }^{3}$ Two observations were excluded from data analysis due to failure to complete the experimental task. The remaining 59 participants had an average of 4.05 years of external audit experience. Additionally, 43 (72.88 percent) and 28 (47.46 percent) participants had experience with auditing inventory and manufacturing firms, respectively. All the participants had extensive experience using analytical procedures to obtain audit evidence. Participants' demographic information did not significantly differ between the treatments and is excluded from further consideration. ${ }^{4}$

\section{Research Instrument}

The experimental case was adapted from the one used by Asare and Wright. Prior studies using this case to examine analytical procedures indicated that the fluctuation pertaining to the client's unaudited balance warranted further investigation and did not evaluate expectation formation (Asare and Wright 1995; Asare and Wright 1997; Asare et al. 2000; Asare and Wright 2003; Green and Trotman 2003; Green 2004). To achieve our goal of determining how a biased (versus unbiased) expectation influences an analytical procedure, we revised the case to require participants to create and evaluate their own analytical expectation, as well as investigate the current-year fluctuation.

The case involved performing an analytical procedure on current-year gross profit, which fluctuated significantly from prior-year balances. ${ }^{5}$ The client's current-year gross profit was reported at $\$ 20,026,000$ and represented a 15.33 percent increase compared to the prior year. In the case, gross profit was misstated by $\$ 1$ million, which was 5.3 percent of unadjusted gross profit and material to the audit. The seeded error in the financial statements resulted from management's failure to appropriately adjust standard costs to actual costs incurred during the period. The case was based on an actual audit engagement and had been validated by audit partners, audit managers, and prior research utilizing the case to examine analytical procedures (Asare and Wright 1995; Asare and Wright 1997; Asare et al. 2000; Asare and Wright 2003; Green and Trotman 2003; Green 2004).

Our experiment consisted of a $2 \times 1$ between-participants experimental design where we manipulated whether analytical expectations were formed with (versus without) knowledge of current-year figures. After random assignment, 31 individuals were assigned to the with-unauditedbalances treatment and 28 individuals were assigned to the without-unaudited-balances treatment. All auditors were initially provided with background information about the client, three previous

\footnotetext{
3 Trompeter and Wright's (2010) survey of auditors' use of analytical procedures indicates seniors and managers design the overwhelming majority of analytical procedures. Thus, our sample of experienced seniors is appropriate for the experimental case.

4 The covariates of gender, external audit experience, inventory audit experience, and manufacturing company audit experience were considered in our analyses and did not change our results statistically or inferentially. These are the same covariates included in prior research that used an earlier version of the experimental instrument (Asare and Wright 1995; Asare and Wright 1997; Asare et al. 2000; Asare and Wright 2003).

5 While it is more common to perform analytical procedures on account balances, the redrafted version of SAS No. 56 Analytical Procedures (AICPA 2012) indicates an analytical procedure can be performed on recorded amounts within the financial statements or ratios. Moreover, the PCAOB's $(2008 \mathrm{~b}, 2011)$ inspection process found deficiencies in the execution of analytical procedures over gross profit, thus providing evidence that our experimental case reflects practice.
} 
years of audited financial statements, and selected financial ratios. This information should be the basis for creating an expectation for current-year gross profit. The experimental manipulation consisted of either supplying or restricting access to the company's unaudited financial information, including current-year gross profit.

An expectation for the company's current-year gross profit could be arrived at in the experimental case by applying the trend in sales growth to the sales figure reported in the prior year. Then the historical gross profit percentage for the company could be applied to the expected sales figure. Using this basis, which did not consider current-year figures, one would likely develop a gross profit expectation between $\$ 18$ million and $\$ 18.8$ million, based upon the assumptions made by the auditor. These amounts were more in line with the client's correct gross profit balance and were significantly less than the reported amount that is materially misstated. The completion of the gross profit expectation represented the end of the first part of the experiment.

The second part of the experiment was the same for all participants, and the client's currentyear financial information was made available to both treatments. Regardless of the participants' initial assessments of gross profit, the experiment indicated that the manager on the engagement considered the fluctuation to be significant and requested that the senior-in-charge further investigate the balance. This was the mechanism within the experimental design that ensured all participants investigated the change in gross profit, regardless of their initial expectations. This manager request is consistent with practice, as Roebuck and Trotman (1992) found that 82 percent of all manager review comments required additional or follow-up audit work. Similarly, Trompeter and Wright (2010) found that auditors often use analytical procedures in conjunction with more detailed testing.

To aid the participants in the additional investigation, the experiment supplied them with five potential hypotheses (causes) and the participants were told that the hypotheses were developed by competent audit staff. ${ }^{6}$ The first (decrease in raw material prices) and fourth (shift in sales mix toward higher-grossing products) hypotheses were non-error explanations for the fluctuation, suggesting the balance was reasonably stated. The remaining three hypotheses (purchase cutoff errors, standard costs not updated, and misallocation of administration costs) asserted that the fluctuation was unusual and attributed this to an error in the financial statements.

Next, participants had the opportunity to review more information about each of the possible causes to ascertain which most likely explained the change in the client's gross profit. The additional information consisted of specific audit procedures-and their corresponding resultsrelated to each of the supplied hypotheses. There was a one-to-one relationship between the potential causes and subsequent audit procedures. That is, for each cause, there was exactly one audit procedure designed to test the plausibility of that hypothesis. However, the results of the audit procedures were not so obvious that everyone would identify the correct hypothesis, as each audit procedure did not completely disconfirm or confirm the corresponding hypothesis (Asare and Wright 2003). Following the examination of additional information, the participants revisited the proposed causes and selected the one that most likely explains the company's change in gross profit. They also provided a final assessment as to whether gross profit was reasonably stated.

\footnotetext{
${ }^{6}$ Consistent with prior research employing this instrument (Asare and Wright 1995; Asare and Wright 1997; Asare et al. 2000; Asare and Wright 2003; Green and Trotman 2003; Green 2004), the auditor participants inherited rather than self-generated the hypotheses. However, this inheriting of hypotheses is congruent with audit practice, whereby explanations are sometimes identified by peers or superiors, by the client, from research, or from industry trends. Moreover, the prior studies using this instrument referred to this step as "hypothesis generation." Since the participants do not generate their own hypotheses, we refer to it as the initial evaluation of hypotheses.
} 


\section{TABLE 1}

\section{Manipulation Check Analysis}

Panel A: Gross Profit Expectation Analysis

\begin{tabular}{|c|c|c|c|c|c|}
\hline & $\begin{array}{c}\text { With } \\
\text { Unaudited } \\
\text { Balances }\end{array}$ & $\begin{array}{l}\text { Without } \\
\text { Unaudited } \\
\text { Balances }\end{array}$ & df & t-statistic & $\begin{array}{c}\text { One-Tailed } \\
\text { p-value }\end{array}$ \\
\hline \multicolumn{6}{|l|}{ Gross Profit Expectation: } \\
\hline Mean & 19,736 & 18,091 & 57 & 5.63 & $<0.01$ \\
\hline Standard Deviation & 1,183 & 701 & 57 & 0.75 & 0.46 \\
\hline \multicolumn{6}{|l|}{ Expectation Difference: } \\
\hline Mean & 780 & 1,935 & 57 & 4.50 & $<0.01$ \\
\hline Standard Deviation & 1,183 & 701 & 57 & 1.16 & 0.25 \\
\hline
\end{tabular}

\section{Panel B: Initial Reasonableness Assessment Analysis}

\begin{tabular}{|c|c|c|c|c|c|}
\hline & $\begin{array}{c}\text { With } \\
\text { Unaudited } \\
\text { Balances }\end{array}$ & $\begin{array}{l}\text { Without } \\
\text { Unaudited } \\
\text { Balances }\end{array}$ & df & t-statistic & $\begin{array}{c}\text { One-Tailed } \\
\text { p-value }\end{array}$ \\
\hline \multicolumn{6}{|c|}{ Initial Reasonableness Assessment: } \\
\hline Mean & 6.52 & 4.29 & 57 & 3.86 & $<0.01$ \\
\hline Standard Deviation & 2.63 & 1.76 & 57 & 2.17 & 0.03 \\
\hline
\end{tabular}

Panel A reports the results of the t-tests on the auditors' gross profit expectations and the corresponding difference from the amount the client is trying to report. Point estimate and expectation difference dollar values are in thousands. Panel B reports the t-test comparing the difference in how the auditors initially perceived the reasonableness of the client's reported balance. Reasonableness was measured on a ten-point Likert scale with the endpoints of $1=$ "gross profit is materially misstated" and $10=$ "gross profit is reasonably stated."

\section{RESULTS}

\section{Preliminary Analysis and Manipulation Checks}

Prior to analyzing our theoretical hypotheses, we first assessed the validity of the obtained data. This consisted of examining the instrument's manipulation checks, the knowledge of the participants, and their motivation toward the task. Our manipulation checks consisted of (1) evaluating whether the knowledge of unaudited balances translated into biased expectations, and (2) analyzing participants' responses to manipulation check questions. In regard to the creation of biased estimates, we captured the dependent variable of a gross profit expectation (or point estimate) and calculated the difference between the participant's gross profit expectation and the client's current-year gross profit balance. Smaller expectation differences from participants in the treatment with knowledge of current-year financial information would indicate bias in expectation formation. ${ }^{7}$ As detailed in Panel A of Table 1, we found significant differences in the mean gross profit point estimate $\left(\mathrm{t}_{57}=5.63, \mathrm{p}<0.01\right)$ and the expectation difference $\left(\mathrm{t}_{57}=4.50, \mathrm{p}<0.01\right)$ between the treatments, indicating a bias in analytical expectations consistent with prior literature

\footnotetext{
${ }^{7}$ Expectation difference was defined as the absolute dollar value difference between the participant's current-year expectation for gross profit and the amount the client was trying to report in the current year.
} 
(Kinney and Uecker 1982; Biggs and Wild 1985; Heintz and White 1989; McDaniel and Kinney 1995; Heintz et al. 1999).

As a validation of our manipulation, we also compared how reasonable the participants found the client's unaudited balance after their expectation calculations. This analysis is presented in Panel B of Table 1. If a bias were present in expectation formation, then it would likely translate into greater favorability toward the client's balance. Using a dependent variable measure of a tenpoint Likert scale with the endpoints of $1=$ "gross profit is materially misstated" and $10=$ "gross profit is reasonably stated," we found that participants with knowledge of unaudited balances initially viewed the client's gross profit as significantly more reasonable than participants without such information $\left(\mathrm{t}_{57}=3.86, \mathrm{p}<0.01\right)$.

In addition to this analysis pertaining to the point estimate, we found that all of the participants correctly responded to both of the manipulation check questions. The manipulation check questions consisted of asking the participants if current-year gross profit and current-year net income were present during their expectation formation.

The majority of participants (76 percent) correctly answered all three knowledge questions regarding how to perform analytical procedures, with the remaining participants correctly answering two of the three questions. ${ }^{8}$ We also assessed the participants' motivation to complete the experiment by measuring how interesting they thought the case was and the perceived effort they put into completing it. The mean interest response was 6.32 and effort response was 6.75 on a ten-point response scale, where higher values represent more interest/effort. More importantly, there were no significant differences in mean responses between treatments for the motivation questions. Based on the above analysis, it appears the two treatments were homogenous, the manipulation was correctly perceived by the participants and resulted in biased expectations and differing perceptions toward the client's balance, the participants were sufficiently knowledgeable to perform the experimental task, and the participants found the project to be interesting and put a reasonable amount of effort into completing it. As a result, no adjustments were made to the data set based on the participants' responses.

\section{Tests of Hypotheses}

\section{Hypothesis 1}

$\mathrm{H} 1$ concerns how auditors initially evaluated the inherited hypotheses explaining the change in the client's balance. The participants reported their perceived likelihood that each cause explains the variation in the client's gross profit on a ten-point Likert scale with the endpoints of $1=$ "NOT likely cause for fluctuation" and $10=$ "likely cause for fluctuation." The descriptive statistics and our statistical analysis for $\mathrm{H} 1$ are presented in Table 2.

$\mathrm{H} 1$ predicts auditors with knowledge of unaudited balances will assign a greater likelihood of explanation to the non-error causes as compared with auditors without current-year figures during expectation formation. We tested $\mathrm{H} 1$ by comparing the mean likelihood response for the non-error causes versus the error causes, both between and within each treatment group. The mean likelihood response for non-error and error causes was created by averaging the non-error (two responses) and error (three responses) measures from each participant. This analysis is reported in Panel B of Table 2. Consistent with our theoretical predictions, participants in the with-unaudited-balances treatment found the non-error causes significantly more likely than the error causes $\left(\mathrm{t}_{60}=4.41 ; \mathrm{p}<0.01\right)$. Moreover, these auditors perceived the non-error causes as significantly more likely than the

\footnotetext{
${ }^{8}$ The number of participants who missed one of the three knowledge questions was randomly distributed between the two treatments. Moreover, the exclusion of these observations did not change the results of the following analysis.
} 


\section{TABLE 2}

\section{Likelihood Evaluation of Inherited Hypotheses}

\section{Panel A: Descriptive Statistics}

\begin{tabular}{|c|c|c|c|c|c|}
\hline & Cause 1 & Cause 2 & Cause 3 & Cause 4 & Cause 5 \\
\hline With Unaudited Balances & 6.00 & 4.32 & 5.03 & 7.16 & 4.84 \\
\hline Without Unaudited Balances & 5.36 & 4.75 & 5.43 & 6.25 & 5.32 \\
\hline
\end{tabular}

\section{Panel B: Mean (Std. Dev.) Likelihood Response by Type of Error}

\begin{tabular}{|c|c|c|c|c|}
\hline & Error & Non-Error & Difference & $\begin{array}{l}\text { t-statistic } \\
\text { (p-value) }\end{array}$ \\
\hline With Unaudited Balances & $\begin{array}{c}4.73 \\
(2.12)\end{array}$ & $\begin{array}{c}6.58 \\
(2.34)\end{array}$ & $\begin{array}{c}1.85 \\
(2.37)\end{array}$ & $\begin{array}{l}\mathrm{t}_{60}=4.41 \\
(<0.01)\end{array}$ \\
\hline Without Unaudited Balances & $\begin{array}{c}5.17 \\
(2.24)\end{array}$ & $\begin{array}{c}5.81 \\
(2.35)\end{array}$ & $\begin{array}{c}0.64 \\
(2.13)\end{array}$ & $\begin{array}{c}\mathrm{t}_{54}=1.36 \\
(0.17)\end{array}$ \\
\hline $\begin{array}{l}\text { t-statistic } \\
\text { p-value }\end{array}$ & $\begin{array}{c}\mathrm{t}_{57}=1.08 \\
(0.28)\end{array}$ & $\begin{array}{c}\mathrm{t}_{57}=1.99 \\
\quad(0.05)\end{array}$ & $\begin{array}{c}\mathrm{t}_{57}=2.15 \\
\quad(0.04)\end{array}$ & \\
\hline
\end{tabular}

Panel A reports the descriptive statistics from the auditors' initial evaluation of the possible causes explaining the fluctuation in gross profit. Cause $1=$ decrease in raw material prices (non-error). Cause $2=$ purchase cutoff errors (error). Cause $3=$ standard costs not updated (error, correct cause). Cause $4=$ shift in sales mix toward higher-grossing products (non-error). Cause $5=$ misallocation of administration costs (error). Panel B reports the mean responses by type of error and the corresponding t-tests comparing the differences both between and within each treatment. Likelihood was measured on a ten-point Likert scale with the endpoints of $1=$ "NOT likely cause for fluctuation" and $10=$ "likely cause for fluctuation."

without-unaudited-balances treatment $\left(\mathrm{t}_{57}=1.99 ; \mathrm{p}=0.05\right)$. There was no significant difference in how the without-unaudited-balances treatment assigned likelihood to the error and non-error causes $\left(\mathrm{t}_{54}=1.36 ; \mathrm{p}=0.17\right)$. Additionally, the likelihood responses corresponding to the error causes did not differ significantly between the treatments $\left(t_{57}=1.08 ; \mathrm{p}=0.28\right)$. The results, taken as a whole, support the $\mathrm{H} 1$ predictions and demonstrate a significant difference in how the treatment groups viewed the potential causes for the change in gross profit.

\section{Hypothesis 2}

$\mathrm{H} 2$ involves the investigation stage of information search. The instrument captured the dependent variable of the perceived relevance of each audit procedure in identifying the cause for the change in gross profit. Specifically, the experimental instrument captured each participant's ranking of the audit procedures (from 1 to 5) based on the relevance of each procedure to the decision task. ${ }^{9}$ The descriptive statistics and our statistical analysis for $\mathrm{H} 2$ are presented in Table 3.

$\mathrm{H} 2$ posits auditors with unaudited balances will assign greater weight to the non-errorsupporting additional information, while auditors without unaudited balances will give greater weight to the additional information correctly depicting the error in the financial statements. Like

\footnotetext{
${ }^{9}$ Before ranking each audit procedure, the instrument requested the participants to consider the importance of each procedure as a mechanism to ensure each piece of information was evaluated.
} 


\section{TABLE 3}

\section{Ranking of Additional Information}

\section{Panel A: Descriptive Statistics}

\begin{tabular}{|c|c|c|c|c|c|}
\hline & Cause 1 & Cause 2 & Cause 3 & Cause 4 & Cause 5 \\
\hline With Unaudited Balances & 3.03 & 3.26 & 2.68 & 2.32 & 3.71 \\
\hline Without Unaudited Balances & 3.17 & 2.78 & 2.00 & 3.07 & 3.96 \\
\hline
\end{tabular}

Panel B: Mean (Std. Dev.) Ranking by Type of Error

\begin{tabular}{|c|c|c|c|c|}
\hline & Error & Non-Error & Difference & $\begin{array}{l}\text { t-statistic } \\
\text { (p-value) }\end{array}$ \\
\hline With Unaudited Balances & $\begin{array}{c}3.22 \\
(0.59)\end{array}$ & $\begin{array}{c}2.68 \\
(0.88)\end{array}$ & $\begin{array}{c}0.54 \\
(1.47)\end{array}$ & $\begin{array}{c}\mathrm{t}_{60}=2.83 \\
(0.01)\end{array}$ \\
\hline Without Unaudited Balances & $\begin{array}{c}2.91 \\
(0.45)\end{array}$ & $\begin{array}{c}3.12 \\
(0.68)\end{array}$ & $\begin{array}{c}0.21 \\
(1.13)\end{array}$ & $\begin{array}{c}\mathrm{t}_{54}=1.36 \\
\quad(0.18)\end{array}$ \\
\hline $\begin{array}{l}\text { t-statistic } \\
\text { p-value }\end{array}$ & $\begin{array}{c}\mathrm{t}_{57}=2.18 \\
(0.03)\end{array}$ & $\begin{array}{c}\mathrm{t}_{57}=2.17 \\
(0.03)\end{array}$ & $\begin{array}{c}\mathrm{t}_{57}=2.18 \\
(0.03)\end{array}$ & \\
\hline
\end{tabular}

Panel A reports the descriptive statistics from the auditors' ranking of additional information corresponding to the provided causes. Cause $1=$ decrease in raw material prices. Cause $2=$ purchase cutoff errors. Cause $3=$ standard costs not updated (correct cause). Cause $4=$ shift in sales mix toward higher-grossing products. Cause $5=$ misallocation of administration costs. Panel B reports mean ranking of the additional information by type of error and the corresponding t-tests comparing the differences both between and within each treatment. Scale is: $1=$ most relevant to $5=$ least relevant.

$\mathrm{H} 1$, we first analyzed $\mathrm{H} 2$ by comparing the mean rankings of the non-error procedures versus the error procedures, both between and within each treatment group. This analysis is presented in Panel B of Table 3. Consistent with the selective accessibility model, participants in the with-unauditedbalances treatment found the non-error additional information to be significantly more relevant than the error-supporting information $\left(\mathrm{t}_{60}=2.83 ; \mathrm{p}=0.01\right)$. These auditors also ranked the audit procedures corresponding to non-error causes as significantly more pertinent than the non-error relevance rankings reported by the without-unaudited-balances treatment $\left(\mathrm{t}_{57}=2.17 ; \mathrm{p}=0.03\right)$. Alternatively, the error-related information was seen as significantly more relevant by the withoutunaudited-balances treatment as compared to the with-unaudited-balances treatment $\left(\mathrm{t}_{57}=2.18 ; \mathrm{p}=\right.$ $0.03)$.

While the previous analysis supports the predicted behavior of auditors with unaudited balances, it does not address whether those in the without-unaudited-balances treatment were more likely to identify and assigned more weight to the additional information that correctly describes the error. To address this question, we examined the proportion of participants who selected the audit procedure corresponding to the correct hypothesis (Cause 3) as the most relevant. Sixteen individuals from the without-unaudited-balances treatment and six individuals from the withunaudited-balances treatment identified this audit procedure as the most relevant, a statistically significant difference $\left(\chi_{1}{ }^{2}=19.32, \mathrm{p}<0.01\right)$. Furthermore, participants in the without-unauditedbalances treatment were significantly more likely to rank the audit procedure associated with the correct cause as most relevant compared with any other audit procedure provided (Cause 1: $\chi_{1}{ }^{2}=$ 
21.22, $\mathrm{p}<0.01$; Cause 2: $\chi_{1}^{2}=17.47, \mathrm{p}<0.01$; Cause 4: $\chi_{1}{ }^{2}=17.51, \mathrm{p}<0.01$; and Cause 5: $\chi_{1}{ }^{2}$ $=23.05, \mathrm{p}<0.01)$. These results support $\mathrm{H} 2$.

\section{Hypothesis 3}

$\mathrm{H} 3$ addresses the final decision stage of hypothesis evaluation. The dependent variable measure for $\mathrm{H} 3$ consisted of the participants selecting the one hypothesis or cause that appeared to best explain the current-year change in gross profit. The results indicated 12.90 percent of the participants in the with-unaudited-balances treatment and 53.57 percent of the participants in the without-unaudited-balances treatment selected the correct cause. ${ }^{10} \mathrm{~A}$ z-test on the difference between the percentage of correct responses from each treatment indicates that the participants in the without-unaudited-balances treatment were significantly more likely to identify the correct cause for the change in gross profit $(\mathrm{z}=3.38, \mathrm{p}<0.01)$. This finding supports the predictions of H3.

In $\mathrm{H} 2$, we identified six individuals from the with-unaudited-balances treatment and 16 individuals from the without-unaudited-balances treatment who correctly selected the most relevant piece of additional information related to the fluctuation. Of the six participants from the with-unaudited-balances treatment, only two (33 percent) identified the correct cause of the fluctuation. Alternatively, a significantly larger proportion, 14 of the 16 (88 percent), of participants from the without-unaudited-balances treatment identified the correct cause $(\mathrm{z}=4.08, \mathrm{p}$ $<0.01)$.

\section{Hypothesis 4}

The experimental instrument also captured the auditors' final gross profit reasonableness assessment on a ten-point Likert scale with the endpoints of $1=$ "gross profit is materially misstated" and $10=$ "gross profit is reasonably stated." Mean responses between the withunaudited-balances $(\mathrm{M}=6.16)$ and without-unaudited-balances $(\mathrm{M}=5.14)$ groups were significantly different $\left(t_{57}=1.69, \mathrm{p}=0.05\right)$. Thus, supporting $\mathrm{H} 4$, participants with knowledge of unaudited balances during expectation formation provided more favorable gross profit assessments after all the components of the analytical procedure were performed.

In a supplemental analysis, we examined whether the difference in final assessments was driven solely by the initial bias in expectation or by the difference in cognitive processing after a biased expectation was created. We accomplished this by performing a path analysis on the direct effect of an initial expectation bias on final assessments and the indirect effect of such a bias on final assessments mediated by how auditors evaluated the hypothesis and information corresponding to the correct cause. This path analysis is presented in Figure 1. The first-order path coefficient for the direct effect is significant and indicates that the knowledge of unaudited values translated into more favorable final reasonableness assessments $\left(\mathrm{F}_{1,58}=2.86, \mathrm{p}=0.09\right)$. The indirect effect is also significant, whereby auditors without unaudited balances during expectation formation focused more of their subsequent investigation on the hypothesis and information pertaining to the correct cause $\left(\mathrm{F}_{1,58}=7.95, \mathrm{p}=0.01\right)$ and, as a result, provided less favorable reasonableness assessments of gross profit $\left(\mathrm{F}_{1,58}=15.37, \mathrm{p}<0.01\right)$. More importantly, the direct effect becomes insignificant when the influence of the mediator is included in the model $\left(F_{1,58}=0.26, p=0.61\right)$. This provides evidence that the procedural difference in cognitive processing drove the final judgments of auditors

10 Of the participants in the with-unaudited-balances treatment, 65 percent selected one of the non-error hypotheses as the most likely cause for the fluctuation in gross profit. Of the without-unaudited-balances participants who did not select the correct cause, 31 percent selected another error cause, and the remaining 15 percent selected non-error causes to explain the fluctuation in gross profit. 


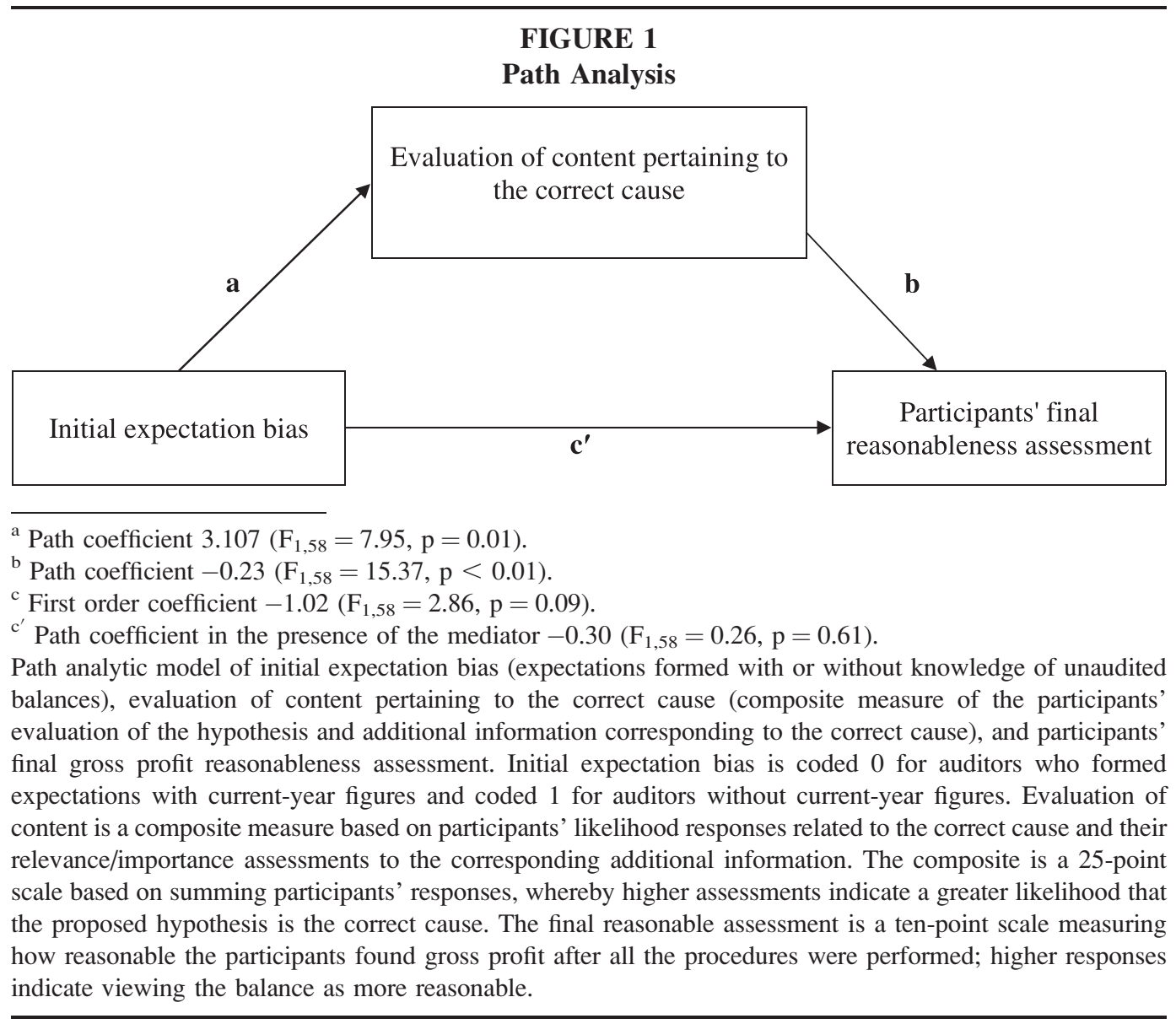

versus merely being a function of a biased estimate at the front end of the sequential process (Sobel test statistic $=-2.19, \mathrm{p}=0.03$ ).

\section{DISCUSSION AND CONCLUSIONS}

Decision makers have difficulty ignoring information that is available, yet irrelevant to their judgments. This problem is particularly prevalent in the use of analytical procedures in auditing. To gain an understanding of how this tendency affects decision-making, we investigated how knowledge of the client's unaudited balances-knowledge that typically leads to biased expectations-influences the process and conclusions reached during auditors' investigation into a fluctuation.

After inducing a bias by making unaudited balances available to auditors during expectation formation, we examined the cognitive process through which auditors investigate a fluctuation. As predicted by the selective accessibility model, we found that auditors with knowledge of current-year figures during expectation formation preferred hypotheses that confirmed the client's balance as reasonably stated. Moreover, these auditors allocated more weight to the additional information that supported the non-error hypotheses. The result was that these auditors were less likely to identify the correct cause behind the change in the client's current-year balance and viewed the balance as more reasonably stated. 
Alternatively, auditors who did not have knowledge of unaudited balances during expectation formation gave equal consideration to all available/competing hypotheses explaining the fluctuation. By doing so, they could better recognize the additional information that was most pertinent to the decision task and, as a result, were more likely to correctly identify the misstatement in the client's gross profit.

Beyond finding that the effectiveness of analytical procedures is negatively impacted when expectations are formed with knowledge of unaudited balances, our mediation analysis demonstrated that the procedural differences in cognitive processing-stemming from the availability of unaudited balances-drove the difference in decision quality between the auditors. In particular, we found that an auditor who has knowledge of unaudited balances and identifies the most relevant piece of information pertaining to the fluctuation only selected the correct cause 33 percent of the time. In contrast, auditors who form expectations without unaudited balances were not only significantly more likely to recognize the most relevant piece of additional information, but also, when they did so, they correctly identified the cause 88 percent of the time, a significant difference $(\mathrm{z}=4.08, \mathrm{p}<0.01)$. Although this analysis is limited due to examining a small subsample, the bias appears to be so pervasive that the identification of the most relevant piece of information alone is not enough to overcome its effects.

This study also supports selective accessibility as a mechanism for explaining numerical anchoring. Our results indicate that the selective activation of target-consistent knowledge is persistent throughout the entire decision task and cannot be overcome by exposure to contradictory information. Finally, we provide one instance of the consequences of numerical anchoring: auditors potentially deem a balance as reasonably stated when a material misstatement exists.

Prior research suggests that requiring auditors to consider additional information that is inconsistent with their initial reasonableness judgments can de-bias, or un-anchor, their judgment (Kennedy 1995). We find that, consistent with selective accessibility, the bias is only slightly diminished when exposed to additional contradictory information. We encourage future research to investigate other means of reducing auditors' potential reliance on client balances. From a practical perspective, it is not possible to simply require auditors to form expectations before viewing any current-year financial information. Moreover, it has been demonstrated that instructions alone (McDaniel and Kinney 1995), as well as accountability and experience (Kennedy 1995), cannot overcome the bias of having knowledge of irrelevant information. Thus, we encourage future researchers to examine mechanisms that have the potential to de-bias auditors' expectations during analytical procedures. Decision aids, in particular, have the potential to improve auditors' judgments during analytical procedures and should be explored by future research. Cognitively, when one is confronted with a challenging decision, it is easier to minimize effort by relying on unaudited balances in conjunction with developing an expectation. An aid could restructure the task and redirect auditors' attention away from the irrelevant target and toward the relevant information, as this intervention has been successful in reducing hindsight bias (Anderson et al. 1997) and the curse of knowledge (Earley et al. 2008).

As a whole, only a limited number of studies have examined auditors' expectations during analytical procedures. Future research could also follow the trend in psychology research and examine additional variables that affect decisions involving numerical anchoring. Some of the factors that can influence auditors' expectations include motivation, attitude, credibility, mood, social influence, and goals.

A limitation of this study is that it did not account for the traditional public accounting review process or the time/budget constraints of an audit. Any negative effects resulting from creating a biased expectation might be found and overcome during the audit review process. Additionally, we imposed no time constraint on our participants. If time was an issue, then a greater number of individuals from the without-unaudited-balances treatment might behave more like the auditors 
with unaudited balances as a result of efficiency pressures. Second, due to the limited nature of the experiment, we provided the participants with a set amount of information. Traditionally, auditors who perform analytical procedures have extensive knowledge of and experience with the client, thereby having a broader base from which to create an analytical expectation. Thus, to some extent, our experimental design mimics analytical procedures performed for a first-year client. This lack of experience with the client is potentially amplified in our experiment, as only half of the participants had experience auditing a manufacturing company, the basis of the experimental case. As a result, this might have made the participants more willing to rely on the unaudited balance during expectation formation. Nevertheless, experience was randomly distributed between the treatments. Next, based on discussions with auditors, some firms have adopted a more structured approach to creating analytical expectations than what was provided in our experimental case. Again, future research examining such an aid would be useful to determine whether it increases analytical procedure effectiveness. Because of the variability in how firms execute analytical procedures, we cannot assess how pervasive the potential problem identified in this study is in practice. Finally, our experiment provided the participants with the possible causes and all additional information related to the fluctuation. This was done to maintain control over the experiment and allow for cleaner data analysis. However, in practice, auditors typically generate their own hypotheses, which can range in number, and decide which additional information to obtain. Because of our experimental design, it is unclear how greater freedom to identify hypotheses and additional information would impact auditors' analytical procedure decisions in the presence of a biased expectation. Future research could pursue this question. Nonetheless, we suspect the self-generation of hypotheses by individuals with knowledge of unaudited balances would translate into explanations supporting the balance as reasonably stated. Thus our experimental design that included a balanced strategy, which forced the consideration of conflicting explanations, likely biased against finding results.

Finally, our participants had an average of four years of public accounting audit experience and were experienced seniors. Trompeter and Wright (2010) note that analytical procedures are typically designed by managers and seniors, and performed by seniors and staff. Thus, the procedures are performed by more junior staff now than previously documented (Hirst and Koonce 1996). The lack of variation in experience precludes us from testing for experience effects, but future research may choose to examine the impact of experience on analytical procedure judgments.

\section{REFERENCES}

American Institute of Certified Public Accountants (AICPA). 1988. Analytical Procedures. SAS No. 56. New York, NY: AICPA.

American Institute of Certified Public Accountants (AICPA). 2008. Codification of Auditing Standards (Including AICPA and PCAOB Auditing and Attestation Standards). New York, NY: AICPA.

American Institute of Certified Public Accountants (AICPA). 2012. Analytical Procedures: AICPA Audit Guide. New York, NY: AICPA.

Anderson, J. C., K. K. Moreno, and J. M. Mueller. 2003. The effect of client vs. decision aid as a source of explanations upon auditors' sufficiency judgments: A research note. Behavioral Research in Accounting 15 (1): 1-11.

Anderson, J. C., M. M. Jennings, D. Jordan Lowe, and P. M. J. Reckers. 1997. The mitigation of hindsight bias in judges' evaluation of auditor decisions. Auditing: A Journal of Practice \& Theory 16 (2): 2039.

Anderson, U., and L. Koonce. 1998. Evaluating the sufficiency of causes in audit analytical procedures. Auditing: A Journal of Practice \& Theory 17 (1): 1-12.

Asare, S. K., A. M. Wright, and G. M. Trompeter. 2000. The effect of accountability and time budgets on auditors' testing strategies. Contemporary Accounting Research 17 (4): 539-560. 
Asare, S. K., and A. M. Wright. 1995. Normative and substantive expertise in multiple hypotheses evaluation. Organizational Behavior and Human Decision Processes 64 (2): 171-184.

Asare, S. K., and A. M. Wright. 1997. Hypothesis revision strategies in conducting analytical procedures. Accounting, Organizations and Society 22 (8): 737-755.

Asare, S. K., and A. M. Wright. 2003. A note on the interdependence between hypothesis generation and information search in conducting analytical procedures. Contemporary Accounting Research 20 (2): 235-251.

Bhattacharjee, S., T. Kida, and D. M. Hanno. 1999. The impact of hypothesis set size on the time efficiency and accuracy of analytical review judgments. Journal of Accounting Research 37 (1): 83-100.

Bierstaker, J. L., J. C. Bedard, and S. F. Biggs. 1999. The role of problem representation shifts in auditor decision processes in analytical procedures. Auditing: A Journal of Practice \& Theory 18 (1): 18-36.

Biggs, S. F., and J. J. Wild. 1985. An investigation of auditor judgment in analytical review. The Accounting Review 58 (4): 607-633.

Brewster, B. E. 2012. How a systems perspective improves knowledge acquisition and performance in analytical procedures. The Accounting Review 86 (3): 915-943.

Chapman, G. B., and E. J. Johnson. 1999. Anchoring, activation, and the construction of values. Organizational Behavior and Human Decision Processes 79 (2): 115-153.

Cullinan, C. P., and S. G. Sutton. 2002. Defrauding the public interest: A critical examination of reengineered audit processes and the likelihood of detecting fraud. Critical Perspectives on Accounting 13 (3): 297-310.

Earley C. E., V. B. Hoffman, and J. R. Joe. 2008. Reducing management's influence on auditors' judgments: An experimental investigation of SOX 404 assessments. The Accounting Review 83 (6): $1461-1485$.

Epley, N. 2004. A Tale of Tuned Decks? Anchoring as Accessibility and Anchoring as Adjustment. Malden, MA: Blackwell Publishing.

Epley, N., and T. Gilovich. 2005. When effortful thinking influences judgmental anchoring: differential effects of forewarning and incentives on self-generated and externally provided anchors. Journal of Behavioral Decision Making 18: 199-212.

Epley, N., and T. Gilovich. 2010. Anchoring unbound. Journal of Consumer Psychology 20: 20-24.

Frederick, S., D. Kahneman, and D. Mochon. 2010. Elaborating a simpler theory of anchoring. Journal of Consumer Psychology 20: 17-19.

Green, W. 2004. Impact of the timing of receipt of an inherited explanation on auditors' analytical procedures judgments. Accounting \& Finance 44: 369-392.

Green, W. J., and K. T. Trotman. 2003. An examination of different performance outcomes in an analytical procedures task. Auditing: A Journal of Practice \& Theory 22 (2): 219-235.

Heintz, J. A., and G. B. White. 1989. Auditor judgment in analytical review-Some further evidence. Auditing: A Journal of Practice \& Theory 8 (2): 22-39.

Heintz, J. A., G. B. White, and J. C. Bedard. 1999. The effect of data reliability on the influence of unaudited values in audit analytical procedures. International Journal of Auditing 3 (2): 135-146.

Hirst, E., and L. Koonce. 1996. Audit analytical procedures: A field investigation. Contemporary Accounting Research 13 (2): 457-486.

Kahneman, D. 2003. Maps of bounded rationality: Psychology for behavioral economics. American Economic Review 93 (5): 1449-1475.

Kennedy, J. 1995. Debiasing the curse of knowledge in audit judgment. The Accounting Review 70 (2): 249-273.

Kinney, W. R. Jr., and W. C. Uecker. 1982. Mitigating the consequences of anchoring in auditor judgments. Accounting Review 57 (1): 55-69.

Koonce, L. 1993. A cognitive characterization of audit analytical review. Auditing: A Journal of Practice \& Theory 12 (Supplement): 57-76.

Law, S. B., and R. Willett. 2004. The ability of analytical procedures to signal transaction errors. Managerial Auditing Journal 19 (7): 869-888. 
Lin, K. Z., I. A. M. Fraser, and D. J. Hatherly. 2003. Auditor analytical review judgment: A performance evaluation. The British Accounting Review 35 (1): 19-34.

Luippold, B. L., and T. E. Kida. 2012. The impact of initial information ambiguity on the accuracy of analytical review judgments. Auditing: A Journal of Practice \& Theory 31 (2): 113-129.

McDaniel, L. S., and W. R. Kinney. 1995. Expectation-formation guidance in the auditor's review of interim financial information. Journal of Accounting Research 33 (1): 59-76.

Mueller, J. M., and J. C. Anderson. 2002. Decision aids for generating analytical review alternatives: The impact of goal framing and audit-risk level. Behavioral Research in Accounting 14: 157.

Mussweiler, T. 1997. A Selective Accessibility Model of Anchoring: Linking the Anchoring Heuristic to Hypothesis-Consistent and Semantic Priming. Lengerich, Germany: Pabst.

Mussweiler, T., and F. Strack. 1999a. Comparing is believing: A selective accessibility model of judgment anchoring. European Review of Social Psychology 10.

Mussweiler, T., and F. Strack. 1999b. Hypothesis-consistent testing and semantic priming in the anchoring paradigm: A selective accessibility model. Journal of Experimental Social Psychology 35 (2): 136164.

Mussweiler, T., and F. Strack. 2000a. The use of category and exemplar knowledge in the solution of anchoring tasks. Journal of Personality and Social Psychology 78 (6): 1038-1052.

Mussweiler, T., and F. Strack. 2000b. Numeric judgments under uncertainty: The role of knowledge in anchoring. Journal of Experimental Social Psychology 36 (5): 495-518.

Nelson, M. W. 2005. A review of experimental and archival conflicts-of-interest research in auditing. In Conflicts of Interest: Challenges and Solutions in Law, Medicine, and Organizational Settings, edited by D. A. Moore, D. M. Cain, G. Loewenstein, and M. H. Bazerman, 41-69. Cambridge, U.K.: Cambridge University Press.

O’Donnell, E. 2002. Evidence of an association between error-specific experience and auditor performance during analytical procedures. Behavioral Research in Accounting 14: 179.

O'Donnell, E. 2004. Use of forward versus backward reasoning during audit analytical procedures: Evidence from a computerized-process-tracing field study. Accounting \& Finance 44: 75-95.

O’Donnell, E., and J. D. Perkins. 2011. Assessing risk with analytical procedures: Do system-thinking tools help auditors focus on diagnostic patterns? Auditing: A Journal of Practice \& Theory 30 (4): 273283.

O’Donnell, E., and M. Lehman. 1999. Information processing strategy during analytical procedures: Where and how auditors focus their attention. Accounting Forum 23 (3): 241-273.

Peecher, M. E. 1996. The influence of auditors' justification processes on their decisions: A cognitive model and experimental evidence. Journal of Accounting Research 34 (1): 125-140.

Public Company Accounting Oversight Board (PCAOB). 2007. An Audit of Internal Control over Financial Reporting that Is Integrated with an Audit of Financial Statements. AS No. 5. Washington, DC: PCAOB.

Public Company Accounting Oversight Board (PCAOB). 2008a. Report on the PCAOB's 2004, 2005, 2006, and 2007 Inspections of Domestic Annually Inspected Firms. PCAOB Release No. 2008-008. Washington, DC: PCAOB.

Public Company Accounting Oversight Board (PCAOB). 2008b. Preface to Reports Concerning Annually Inspected Firms. PCAOB Release No. 104-2008-046. Washington, DC: PCAOB.

Public Company Accounting Oversight Board (PCAOB). 2010. Auditing Standards Related to the Auditor's Assessment of and Response to Risk. PCAOB Release No. 2010-004. Washington, DC: PCAOB.

Public Company Accounting Oversight Board (PCAOB). 2011. Order Instituting Disciplinary Proceedings, Making Findings, and Imposing Sanctions. PCAOB Release No. 105-2011-003. Washington, DC: PCAOB.

Ranzilla, S., R. E. Chevalier, G. Herrmann, S. M. Glover, and D. F. Prawitt. 2011. Elevating professional judgment in auditing: The KPMG professional judgment framework. Available at: http://www.scribd. com/doc/105344428/KPMG-monograph 
Robson, K., C. Humphrey, R. Khalifa, and J. Jones. 2007. Transforming audit technologies: business risk audit methodologies and the audit field. Accounting, Organizations and Society 32: 409-438.

Roebuck, P., and K. T. Trotman. 1992. A field study of the review process: Research note. Abacus 28 (2): 200-210.

Russo, J. E. 2010. Understanding the effect of a numerical anchor. Journal of Consumer Psychology 20: $25-27$.

Strack, F., and T. Mussweiler. 1997. Explaining the enigmatic anchoring effect: Mechanisms of selective accessibility. Journal of Personality and Social Psychology 73 (3): 437-446.

Trompeter, G., and A. Wright. 2010. The world has changed-Have analytical procedure practices? Contemporary Accounting Research 27 (2): 669-700.

Tversky, A., and D. Kahneman. 1974. Judgment under uncertainty: Heuristics and biases. Science 185 (4157): 1124-1131.

Wegener, D. T., R. E. Petty, K. L. Blankenship, and B. Detweiler-Bedell. 2010a. Elaboration and numerical anchoring: Implications of attitude theories for consumer judgment and decision making. Journal of Consumer Psychology 20: 5-16.

Wegener, D. T., R. E. Petty, K. L. Blankenship, and B. Detweiler-Bedell. 2010b. Elaboration and numerical anchoring: Breadth, depth, and the role of (non-) thoughtful processes in anchoring theories. Journal of Consumer Psychology 20: 28-32. 